\title{
Relationships between structural and electrical properties in mixed conductors duplex materials in the $\mathrm{ZrO}_{2}-\mathrm{Y}_{2} \mathrm{O}_{3}-\mathrm{TiO}_{2}$ ternary system
}

\author{
M. T. Colomer, ${ }^{1,{ }^{*}}$ S. Díaz-Moreno, ${ }^{2}$ R. Boada,${ }^{3, \dagger}$ M. Maczka, ${ }^{4}$ and J. Chaboy ${ }^{3}$ \\ ${ }^{1}$ Instituto de Cerámica y Vidrio, CSIC, c/Kelsen n ${ }^{\circ}$ 5, 28049 Madrid, Spain \\ ${ }^{2}$ Diamond Light Source Ltd, Harwell Science and Innovation Campus, Didcot, Oxfordshire OX11 ODE, United Kingdom \\ ${ }^{3}$ Instituto de Ciencia de Materiales de Aragón, CSIC-Universidad de Zaragoza, 50009 Zaragoza, Spain \\ ${ }^{4}$ Institute of Low Temperature and Structure Research, Polish Academy of Sciences, P.O. Box 1410, Wroclaw, Poland
}

(Received 5 November 2013; published 4 March 2014)

\begin{abstract}
Duplex materials constituted by $0.50 \mathrm{~mol}$ titania-doped yttria-stabilized zirconia (YSZ) and $0.50 \mathrm{~mol}$ titaniadoped yttria-tetragonal zirconia polycrystalline (YTZP) solid solutions in the $\mathrm{ZrO}_{2}-\mathrm{Y}_{2} \mathrm{O}_{3}-\mathrm{TiO}_{2}$ ternary system can be obtained using different processing strategies. In this study, different amounts of $\mathrm{TiO}_{2}$ dopant and different sintering times have been used for the preparation of the duplex materials: Doping YSZ with $10 \mathrm{~mol} \%$ of $\mathrm{TiO}_{2}$ and sintering in air for $8 \mathrm{~h}(10 \mathrm{Ti} 8 \mathrm{~h})$ and doping $\mathrm{YSZ}$ with $15 \mathrm{~mol} \%$ of $\mathrm{TiO}_{2}$ and sintering in air for $2 \mathrm{~h}$ (15Ti2h) are both successful routes to obtain duplex materials. If we compare the field emission scanning electron microscopy-energy dispersive x-ray analyses of each cubic and each tetragonal solid solution of the two duplex materials, we conclude that the composition of each phase is different from each other, as was expected. The total ionic conductivity of both duplex samples is strongly reduced with respect to that of YSZ, and this reduction increases with the Ti content. In addition, the activation energy for ionic migration in 10Ti8h and 15Ti2h is lower than that for YSZ but higher than that for YTZP, as expected in terms of the relative amount of both YSZ and YTZP fractions in the materials. X-ray absorption spectroscopy (XAS) results, both x-ray absorption near-edge structure and extended $\mathrm{X}$-ray absorption fine structure, show that $\mathrm{Ti}$ is sixfold coordinated in both the cubic and tetragonal phases of the duplex materials, departing from the eightfold coordination expected if a simple substitution at the $\mathrm{Zr}$ sites would take place. The XAS results also point out that the ability of Ti to trap oxygen vacancies in the cubic phase increases as Ti content does, in agreement with the electrical conductivity behavior, which cannot be accounted for in terms of a dilution effect.
\end{abstract}

DOI: 10.1103/PhysRevB.89.094101

PACS number(s): 78.70.Dm, 78.30.-j, 61.05.cj, 72.80.Tm

\section{INTRODUCTION}

Mixed conductors should be able to replace the current state-of-the-art anodes for solid oxide fuel cells (SOFCs). Both ionic and electronic defects are present in nonnegligible concentrations in mixed conductors, and their mobility is so significant that the electrode reaction can proceed at any point on the electrode surface. The usual requirement of a triplephase contact, where electrode, electrolyte, and gas phase are in contact, is replaced by a simple requirement of a two-phase boundary region between electrode (mixed conductor) and gas phase. It is expected that polarization losses associated with the current SOFC anodes would thus be minimized [1].

Mixed conductors based on yttria-stabilized zirconia (YSZ) or yttria-tetragonal zirconia polycrystalline (YTZP) are usually obtained if a significant amount of a mixed valence dopant cation is introduced in solid solution. As is the case for YSZ ( $8 \mathrm{~mol} \% \mathrm{Y}_{2} \mathrm{O}_{3}$ ), YTZP $\left(3 \mathrm{~mol} \% \mathrm{Y}_{2} \mathrm{O}_{3}\right)$ is an oxygen ion conductor, but it was found that above $700{ }^{\circ} \mathrm{C}$, its conductivity was lower than in the cubic phase [2]. In contrast, YTZP material has shown to be a tougher material [3]. These two combined characteristics make Ti-doped YSZ/Ti-doped YTZP duplex materials a very attractive option for application in electrochemical devices, such as matrices in a SOFC

\footnotetext{
*Corresponding author: tcolomer@icv.csic.es

†Current address: Diamond Light Source Ltd, Harwell Science and Innovation Campus, Didcot, Oxfordshire OX11 ODE, United Kingdom.
}

anode. Moreover, the desired properties of these mixed ionic conductors depend on the concentration and local environment of mobile ionic species, i.e. the lattice-oxygen vacancies and vacancy complexes. In order to understand the physical properties of these materials such as diffusion and/or ionic conduction, knowledge of the local structure and short-range order becomes necessary [4].

Most of the research efforts performed in the past have been mainly focused on the electrical properties of mixed conductors based on titania-doped yttria-stabilized zirconia and on the titania-doped yttria-tetragonal zirconia materials [5-14]. In addition, studies of the local environment of mobile ionic species, i.e. the lattice-oxygen vacancies and vacancy complexes, have been only performed for Tidoped YTZP materials [13] but not for Ti-doped YSZ or Ti-doped YTZP/Ti-doped YSZ duplex materials. Materials based on cubic zirconia have higher conductivity than that of Ti-doped YTZP materials at the operation temperature of a SOFC as was mentioned above, and for that reason they should be deeply studied from a structural point of view.

Previous x-ray absorption spectroscopy (XAS) studies, performed at the Ti K-edge in Ti-YTZP $[13,15]$ based on the fingerprint analysis of the $\mathrm{x}$-ray absorption near-edge structure (XANES) part of the spectrum, suggested a fivefold coordination of the $\mathrm{Ti}$ ions and a subsequent loss of centrosymmetry in the Ti-YTZP tetragonal zirconia crystal lattice. Moreover, the analysis of the extended $\mathrm{x}$-ray absorption fine structure (EXAFS) part of the absorption spectrum performed by Capel et al. [15] reported Ti-O distances significantly shorter than the 
main $\mathrm{Zr}-\mathrm{O}$ ones, which implies an increase in the anisotropy of the tetragonal layer structure. In contrast, no similar study exists for the case of the Ti-doped YSZ solid solutions. Hence, the crystal chemistry of $\mathrm{Ti}$ ions, i.e. the site symmetry of the $\mathrm{Ti}$ ones in the cubic zirconia crystal lattice, as well as the location of the oxygen vacancies, has not been studied yet.

This paper is focused on the design of duplex materials constituted by Ti-doped YTZP/Ti-doped YSZ solid solutions. In order to obtain those duplex materials, different processing strategies, such as different amounts of $\mathrm{TiO}_{2}$ doping and different sintering times, have been tested. The accurate determination of the local structural environment of Ti, obtained from XAS measurements at the Ti K-edge, makes possible the determination of the Ti coordination in the two lattices and the effect of the titanium cation on the mobile ionic species. The relationships between the total ionic conductivity of those duplex materials with the Ti-local structure and possible trapping of oxygen vacancies in both phases will be also discussed.

\section{EXPERIMENTAL METHODS}

Taking advantage of the fact that $\mathrm{TiO}_{2}$ additions to YSZ cause not only the formation of a titania-doped YSZ solid solution but also a titania-doped YTZP solid solution [16-18], titania doping is one of the strategies employed in this study for the synthesis of duplex materials. The use of different sintering times was also used as an additional variable.

Here, $\quad\left[\left(\mathrm{ZrO}_{2}\right)_{0.92}\left(\mathrm{Y}_{2} \mathrm{O}_{3}\right)_{0.08}\right]_{0.90}\left(\mathrm{TiO}_{2}\right)_{0.10} \quad$ and $\left[\left(\mathrm{ZrO}_{2}\right)_{0.92}\left(\mathrm{Y}_{2} \mathrm{O}_{3}\right)_{0.08}\right]_{0.85}\left(\mathrm{TiO}_{2}\right)_{0.15}$ samples were prepared by addition of $\mathrm{TiO}_{2}$ (Merck, 808, Darmstadt, Germany; average particle diameter of $0.3 \mu \mathrm{m}$ and SSA of $9 \pm 1 \mathrm{~m}^{2} / \mathrm{g}$ ) to commercially available YSZ powders (yttria-stabilized zirconia containing $8 \mathrm{~mol} \% \mathrm{Y}_{2} \mathrm{O}_{3}$, Tosoh Co, Tokyo, Japan). The YTZP sample was prepared from commercially available powder [yttria-tetragonal zirconia polycrystalline (3 mol\% $\mathrm{Y}_{2} \mathrm{O}_{3}$ ), Tosoh Co, Tokyo, Japan]. Both YSZ and YTZP powders have average particle diameters of $0.4 \mu \mathrm{m}$ and a specific surface area of $7 \pm 1 \mathrm{~m}^{2} / \mathrm{g}$ and $15 \pm 2 \mathrm{~m}^{2} / \mathrm{g}$, respectively. The $\left(\mathrm{ZrO}_{2}\right)_{0.86}\left(\mathrm{Y}_{2} \mathrm{O}_{3}\right)_{0.02}\left(\mathrm{TiO}_{2}\right)_{0.12} \quad(2 \mathrm{Y} 12 \mathrm{~T})$ samples were prepared from zirconium oxide (prepared by coprecipitation from zirconium oxychloride: $\mathrm{ZrOCl}_{2} \cdot 8 \mathrm{H}_{2} \mathrm{O}$, $99.9 \%$, Alfa Aesar, Karlsruhe, Germany), yttrium oxide (99.9\%, Johnson Matthey $\mathrm{GmbH}$, England), and titanium oxide powders (Merck, 808, Darmstadt, Germany). The particle size distribution was determined with a laser diffraction analyzer (Mastersizer S, Malvern, Worcerstershire,
United Kingdom), and the specific surface area was measured by the $\mathrm{N}_{2}$ adsorption method (Monosorb Surface Area Analyzer MS13, Quantachrome Co., FL, USA). The powder mixtures were submitted to attrition milling for $2 \mathrm{~h}$, sieved $(63 \mu \mathrm{m})$ and calcined at $800^{\circ} \mathrm{C}$ for $2 \mathrm{~h}$ and sieved again (63 $\mu \mathrm{m})$. Finally, the powder was pressed isostatically at $200 \mathrm{MPa}$ into bars which were cut into discs for their characterization.

The samples prepared from $\mathrm{YSZ}$ and $\mathrm{TiO}_{2}$ were sintered in air at $1500{ }^{\circ} \mathrm{C}$ for sintering times of $2,4,8$, and $16 \mathrm{~h}$ (heating and cooling rate $5^{\circ} \mathrm{C} / \mathrm{min}$ ) in order to test the necessary processing conditions to obtain duplex materials. Samples are labeled YSZ, 10Ti2h, 10Ti4h, 10Ti8h, 10Ti16h, and 15Ti2h (see Table I). The YTZP sample was sintered at $1400^{\circ} \mathrm{C}$ for $2 \mathrm{~h}$ in air (heating and cooling rate $5^{\circ} \mathrm{C} / \mathrm{min}$ ). The $2 \mathrm{Y} 12 \mathrm{~T}$ samples were sintered at $1500{ }^{\circ} \mathrm{C}$ for $2 \mathrm{~h}(2 \mathrm{Y} 12 \mathrm{~T} 2 \mathrm{~h})$ and $120 \mathrm{~h}(2 \mathrm{Y} 12 \mathrm{~T} 120 \mathrm{~h})$ in air (heating rate $5^{\circ} \mathrm{C} / \mathrm{min}$ ) and quenched in air in order to avoid the tetragonal to monoclinic transformation. Here, YSZ and YTZP samples have been considered for comparison when an evaluation of the conductivity in air has been performed (ac study).

Final densities were measured by the Archimedes' immersion method in water.

X-ray diffraction (XRD) patterns of the samples were obtained using a Siemens D-5000 Diffractometer (Munich, Germany) and monochromated $(\lambda=1.5406)$ high-intensity $\mathrm{Cu}-\mathrm{K} \alpha_{1}$ radiation. The experimental diffraction patterns were collected at room temperature over a range of $20 \leq 2 \Theta \leq 100$ (step-scanned at $1^{\circ} / 5 \mathrm{~s}$ ). The XRD patterns obtained were analyzed using the diffraction files of $\mathrm{Zr}_{0.8} \mathrm{Y}_{0.2} \mathrm{O}_{1.9}$ (JCPDS 01-082-1246) for the cubic phase, $\mathrm{Zr}_{0.92} \mathrm{Y}_{0.08} \mathrm{O}_{1.96}$ (JCPDS 048-0224, JCPDS 01-083-0113, and JCPDS 17-923) for the tetragonal phase, $\mathrm{ZrO}_{2}$ (JCPDS 037-1484) for the monoclinic phase, and $\mathrm{Y}_{2} \mathrm{Ti}_{2} \mathrm{O}_{7}$ (JCPDS 01-071-2065) for the pyrochlore phase. The XRD patterns of the pellets were used to calculate lattice parameters and phase distributions.

The phase distributions (in mol fraction) in the sintered materials were determined by the ratio [19]:

$$
\frac{M_{c}}{M_{t}}=0.88\left[\frac{I_{c}(400)}{I_{t}(400)+I_{t}(004)}\right] .
$$

The experimental diffraction patterns for the phase distribution calculations were collected at room temperature over a range of $71 \leq 2 \Theta \leq 75$ (step-scanned at $0.025^{\circ} / 20 \mathrm{~s}$ ). Furthermore, phase identification was also performed by Fourier transform (FT)-Raman spectroscopy using a Bruker

TABLE I. Compositions considered in this work.

\begin{tabular}{lccr}
\hline \hline Material & Label & Sintering temperature $\left({ }^{\circ} \mathrm{C}\right) /$ sintering time $(\mathrm{h})$ & Relative density $(\%)$ \\
\hline$\left(\mathrm{ZrO}_{2}\right)_{0.92}\left(\mathrm{Y}_{2} \mathrm{O}_{3}\right)_{0.08}$ & $\mathrm{YSZ}$ & $1500^{\circ} \mathrm{C} / 2 \mathrm{~h}$ & $93.0 \pm 0.5$ \\
{$\left[\left(\mathrm{ZrO}_{2}\right)_{0.92}\left(\mathrm{Y}_{2} \mathrm{O}_{3}\right)_{0.08}\right]_{0.90}\left(\mathrm{TiO}_{2}\right)_{0.10}$} & $10 \mathrm{Ti} 2 \mathrm{~h}$ & $1500{ }^{\circ} \mathrm{C} / 2 \mathrm{~h}$ & $99.9 \pm 0.5$ \\
{$\left[\left(\mathrm{ZrO}_{2}\right)_{0.92}\left(\mathrm{Y}_{2} \mathrm{O}_{3}\right)_{0.08}\right]_{0.90}\left(\mathrm{TiO}_{2}\right)_{0.10}$} & $10 \mathrm{Ti} 4 \mathrm{~h}$ & $1500^{\circ} \mathrm{C} / 4 \mathrm{~h}$ & $99.9 \pm 0.5$ \\
{$\left[\left(\mathrm{ZrO}_{2}\right)_{0.92}\left(\mathrm{Y}_{2} \mathrm{O}_{3}\right)_{0.08}\right]_{0.90}\left(\mathrm{TiO}_{2}\right)_{0.10}$} & $10 \mathrm{Ti} 8 \mathrm{~h}$ & $1500^{\circ} \mathrm{C} / 8 \mathrm{~h}$ & $99.9 \pm 0.5$ \\
{$\left[\left(\mathrm{ZrO}_{2}\right)_{0.92}\left(\mathrm{Y}_{2} \mathrm{O}_{3}\right)_{0.08}\right]_{0.90}\left(\mathrm{TiO}_{2}\right)_{0.10}$} & $10 \mathrm{Ti} 16 \mathrm{~h}$ & $1500^{\circ} \mathrm{C} / 16 \mathrm{~h}$ & $99.9 \pm 0.5$ \\
{$\left[\left(\mathrm{ZrO}_{2}\right)_{0.92}\left(\mathrm{Y}_{2} \mathrm{O}_{3}\right)_{0.08}\right]_{0.85}\left(\mathrm{TiO}_{2}\right)_{0.15}$} & $15 \mathrm{Ti} 2 \mathrm{~h}$ & $1500^{\circ} \mathrm{C} / 2 \mathrm{~h}$ & $99.9 \pm 0.5$ \\
$\left(\mathrm{ZrO}_{2}\right)_{0.97}\left(\mathrm{Y}_{2} \mathrm{O}_{3}\right)_{0.03}$ & $\mathrm{YTZP}$ & $1400^{\circ} \mathrm{C} / 2 \mathrm{~h}$ & $94.0 \pm 0.5$ \\
$\left(\mathrm{ZrO}_{2}\right)_{0.86}\left(\mathrm{Y}_{2} \mathrm{O}_{3}\right)_{0.02}\left(\mathrm{TiO}_{2}\right)_{0.12}$ & $2 \mathrm{Y} 12 \mathrm{~T} 2 \mathrm{~h}$ & $1400^{\circ} \mathrm{C} / 2 \mathrm{~h}(\mathrm{quenching})$ & $99.9 \pm 0.5$ \\
$\left(\mathrm{ZrO}_{2}\right)_{0.86}\left(\mathrm{Y}_{2} \mathrm{O}_{3}\right)_{0.02}\left(\mathrm{TiO}_{2}\right)_{0.12}$ & $2 \mathrm{Y} 12 \mathrm{~T} 120 \mathrm{~h}$ & $1400^{\circ} \mathrm{C} / 120 \mathrm{~h}(\mathrm{quenching})$ & $99.9 \pm 0.5$ \\
\hline \hline
\end{tabular}


FT 100/S spectrometer (Karlsruhe, Germany) with the neodymium-doped yttrium aluminum garnet laser excitation $(1064 \mathrm{~nm})$ and a spectral resolution of $2 \mathrm{~cm}^{-1}$.

The microstructure of the sintered samples was analyzed on polished (down to $1 \mu \mathrm{m}$ ) and thermally etched surfaces $\left(1490^{\circ} \mathrm{C}\right.$ for $6 \mathrm{~min}$, heating and cooling rates of $10^{\circ} \mathrm{C} / \mathrm{min}$ ) by means of field-emission scanning electron microscopy-energy dispersive X-ray (FE-SEM-EDX) analyses (Hitachi S-4700 type I, Tokyo, Japan).

Samples prepared as pellets of $0.8-\mathrm{cm}$ diameter and $0.2-\mathrm{cm}$ thickness, were electroded with platinum high-conductivity paste (Engelhard 6082, USA) on both sample surfaces. Electrochemical impedance spectroscopy analyses were performed in air. The impedance analyzer used was a HP 4192A (Palo Alto, CA, USA) in the frequency range of 10 to $10^{7} \mathrm{~Hz}$.

$\mathrm{X}$-ray absorption spectroscopy data were collected at the Ti K-edge (4966 eV), Y K-edge (17 038 eV), and Zr K-edge $(17998 \mathrm{eV})$ at the Versatile X-ray Absorption Spectroscopy Beamline, I20, at Diamond Light Source. The synchrotron was operating at a ring current of $300 \mathrm{~mA}$ in top-up mode. The measurements were performed at room temperature in fluorescence mode using a 64-element monolithic germanium detector. An ion chamber filled with the appropriate mixture of gases to absorb $20 \%$ of the radiation was placed before the sample and used as an incident beam monitor. Harmonic rejection was achieved by using four rhodium-coated mirrors operating at an incident angle of $2.3 \mathrm{mad}$. In the case of the titanium measurements, two additional silicon mirrors operating at $5 \mathrm{mrad}$ incident angle were used.

The XANES spectra were normalized to the absorption coefficient at high energy $(\sim 100 \mathrm{eV}$ above the edge $)$ to eliminate thickness dependence. The EXAFS signals were extracted following standard procedures [20] using the program ATHENA within the IFEEFIT package [21]. The quantitative EXAFS analyses were performed by using the VIPER program [22] and the phase and amplitude transferability method [23,24]. The backscattering amplitude, phase, and photoelectron mean free path factors were obtained from the experimental EXAFS spectra of reference compounds; the cubic 10\% mol YSZ (c-10) for the $\mathrm{Zr}$ and $\mathrm{Y} \mathrm{K}$-edges and $\mathrm{Y}_{2} \mathrm{Ti}_{2} \mathrm{O}_{7}$ pyrochlore for the Ti K-edge. For the sake of completeness, the same class of analysis was made by using theoretical phases and amplitudes calculated by the FEFF-6 code [25], and fits to the experimental data were carried out in R-space with the ARTEMIS program [21]. No difference was found in the results obtained by both methods.

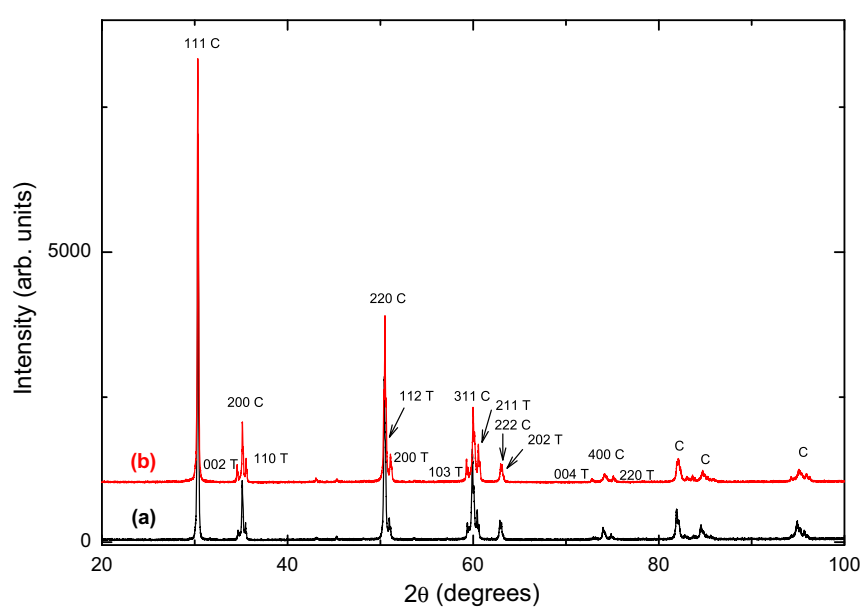

FIG. 1. (Color online) XRD patterns of (a) 10Ti8h and (b) 15Ti2h showing the characteristic reflections of both Ti-doped YSZ solid solutions (labeled as C) and Ti-doped YTZP solid solutions (labeled as $\mathrm{T})$.

\section{RESULTS AND DISCUSSION}

\section{A. X-ray diffraction}

The quantitative analysis performed according to Eq. (1) gave the molar fractions of cubic and tetragonal phases for the different studied compositions (Table II). The pyrochlore phase has not been considered for those quantitative analyses since peaks of that phase are not detected by XRD. The calculations gave $0.50 \mathrm{~mol}$ fraction of titania-doped YSZ solid solution and $0.50 \mathrm{~mol}$ fraction of titania-doped YTZP solid solution for the 10Ti8h sample and $0.51 \mathrm{~mol}$ fraction of Ti-YTZP and 0.49 mol fraction of the cubic phase for 15Ti2h sample. As can be seen in Table II, only these two compositions, 10Ti8h and $15 \mathrm{Ti} 2 \mathrm{~h}$, are duplex materials. Therefore, we have focused hereafter on the characterization of both 10Ti8h and 15Ti2h samples.

The XRD patterns of both 10Ti8h and 15Ti2h samples after sintering at $1500{ }^{\circ} \mathrm{C}$ for 8 and $2 \mathrm{~h}$, respectively, are represented in Fig. 1. Peaks corresponding to a titania-doped YSZ solid solution and peaks corresponding to a titania-doped YTZP solid solution are clearly observed for both samples (Fig. 1). The peaks that correspond to the cubic phase are shifted down towards lower $\theta$ values with respect to the cubic zirconia pattern. Peaks that correspond to the tetragonal phase are also shifted with respect to the tetragonal zirconia patterns. For the latter phase, the diffraction peaks with Miller indices $h$

TABLE II. Molar fractions of cubic and tetragonal solid solutions in the materials prepared [according to Eq. (1)].

\begin{tabular}{lccc}
\hline \hline Material (nominal composition) & Label & Molar fraction of cubic solid solution & Molar fraction of tetragonal solid solution \\
\hline$\left(\mathrm{ZrO}_{2}\right)_{0.92}\left(\mathrm{Y}_{2} \mathrm{O}_{3}\right)_{0.08}$ & $\mathrm{YSZ}$ & 1.00 & 0.00 \\
{$\left[\left(\mathrm{ZrO}_{2}\right)_{0.92}\left(\mathrm{Y}_{2} \mathrm{O}_{3}\right)_{0.08}\right]_{0.90}\left(\mathrm{TiO}_{2}\right)_{0.10}$} & $10 \mathrm{Ti} 2 \mathrm{~h}$ & 0.72 & 0.28 \\
{$\left[\left(\mathrm{ZrO}_{2}\right)_{0.92}\left(\mathrm{Y}_{2} \mathrm{O}_{3}\right)_{0.08}\right]_{0.90}\left(\mathrm{TiO}_{2}\right)_{0.10}$} & $10 \mathrm{Ti} 4 \mathrm{~h}$ & 0.68 & 0.32 \\
{$\left[\left(\mathrm{ZrO}_{2}\right)_{0.92}\left(\mathrm{Y}_{2} \mathrm{O}_{3}\right)_{0.08}\right]_{0.90}\left(\mathrm{TiO}_{2}\right)_{0.10}$} & $10 \mathrm{Ti} 8 \mathrm{~h}$ & 0.50 & 0.50 \\
{$\left[\left(\mathrm{ZrO}_{2}\right)_{0.92}\left(\mathrm{Y}_{2} \mathrm{O}_{3}\right)_{0.08}\right]_{0.90}\left(\mathrm{TiO}_{2}\right)_{0.10}$} & $10 \mathrm{Ti} 16 \mathrm{~h}$ & 0.59 & 0.41 \\
{$\left[\left(\mathrm{ZrO}_{2}\right)_{0.92}\left(\mathrm{Y}_{2} \mathrm{O}_{3}\right)_{0.08}\right]_{0.85}\left(\mathrm{TiO}_{2}\right)_{0.15}$} & $15 \mathrm{Ti} 2 \mathrm{~h}$ & 0.49 & 0.51 \\
$\left(\mathrm{ZrO}_{2}\right)_{0.97}\left(\mathrm{Y}_{2} \mathrm{O}_{3}\right)_{0.03}$ & $\mathrm{YTZP}$ & 0.00 & 1.00 \\
$\left(\mathrm{ZrO}_{2}\right)_{0.86}\left(\mathrm{Y}_{2} \mathrm{O}_{3}\right)_{0.02}\left(\mathrm{TiO}_{2}\right)_{0.12}$ & $2 \mathrm{Y} 12 \mathrm{~T} 2 \mathrm{~h}$ & 0.00 & 1.00 \\
$\left(\mathrm{ZrO}_{2}\right)_{0.86}\left(\mathrm{Y}_{2} \mathrm{O}_{3}\right)_{0.02}\left(\mathrm{TiO}_{2}\right)_{0.12}$ & $2 \mathrm{Y} 12 \mathrm{~T} 12 \mathrm{~h}$ & 0.00 & 1.00 \\
\hline \hline
\end{tabular}


00 show a shift down to lower $d$ values, whereas the 0001 peaks are shifted up to higher $\theta$ values. If we compare the position of the diffraction peak for a given Miller index of each solid solution for the two duplex materials they show a slight shift with respect to each other. This is expected since the composition of each cubic and tetragonal solid solution between them is different. This has been further checked by FE-SEM-EDX (see Subsec. C)

Table III summarizes the lattice parameters, $a_{c}$ for the cubic solid solutions and $a_{t}$ and $c_{t}$ for the tetragonal solid solutions. In the first case, the lattice parameter $a_{c}$ decreases with increasing titania content. In the case of the tetragonal symmetry, the lattice parameter $a_{t}$ decreases and the lattice parameter $c_{t}$ increases with increasing titania content. In addition, the tetragonality is slightly higher for the sample with a higher titania content (15Ti2h).

\section{B. Fourier transform-Raman studies}

Raman spectra of both duplex materials are presented in Fig. 2.

The Raman spectrum of 10Ti8h shows bands at 722, 649, $618,458,329,274$, and $150 \mathrm{~cm}^{-1}$. The band at $618 \mathrm{~cm}^{-1}$ is characteristic for the cubic phase of $\mathrm{ZrO}_{2}$, while the bands at 649,458 , and $150 \mathrm{~cm}^{-1}$ can be assigned to tetragonal $\mathrm{ZrO}_{2}$ [26]. A broad band, which appears at $722 \mathrm{~cm}^{-1}$, cannot be assigned to either the tetragonal or the cubic phase of $\mathrm{ZrO}_{2}$. Literature data show, however, that a broad band above $700 \mathrm{~cm}^{-1}$ is often observed in materials containing $\mathrm{RE}_{2} \mathrm{O}_{3}$ $\left(\mathrm{RE}=\right.$ rare earth), $\mathrm{ZrO}_{2}$, and $\mathrm{TiO}_{2}$ due to the presence of a disordered pyrochlore phase [27,28]. Indeed, the high-frequency band has been observed in other $\mathrm{Ti}$ containing pyrochlores and has been interpreted in different ways [23,27,29-31]. Although, all studies agree that it is with no doubt related to disorder-activated oxygen vibration. For instance, for an ordered $\mathrm{Y}_{2} \mathrm{Ti}_{2} \mathrm{O}_{7}$ pyrochlore, the strongest band is observed near $309 \mathrm{~cm}^{-1}$, and three less intense bands are clearly seen at 609,522 , and $448 \mathrm{~cm}^{-1}$ [28]. When $\mathrm{Zr}^{4+}$ ions are partially substituted for $\mathrm{Ti}^{4+}$ ions, Raman bands become broader, and a new, very broad band appears above $700 \mathrm{~cm}^{-1}$ [28]. Moreover, the intensity of the 522 and $448 \mathrm{~cm}^{-1}$ bands decreases with increasing concentration of the $\mathrm{Zr}^{4+}$ ions, and these bands disappear for $\mathrm{Y}_{2} \mathrm{Ti}_{0.6} \mathrm{Zr}_{1.4} \mathrm{O}_{7}$ [28]. Based on the literature data, we assign the 722 and $329 \mathrm{~cm}^{-1}$ bands of 10Ti8h to disordered $\mathrm{Y}_{2} \mathrm{Ti}_{2-y} \mathrm{Zr}_{y} \mathrm{O}_{7}$ pyrochlore phase. Raman spectroscopy cannot provide information on concentration of this phase. We may only conclude that the concentration of this phase is small since the observed bands are significantly smaller than those related to $\mathrm{ZrO}_{2}$. Finally, our spectrum shows also the presence of a strong band at $274 \mathrm{~cm}^{-1}$, and it is known that pure tetragonal $\mathrm{ZrO}_{2}$ shows the presence of a relatively strong Raman band near $257 \mathrm{~cm}^{-1}$ [28]. We assign therefore our band at $274 \mathrm{~cm}^{-1}$ to the tetragonal phase, and the observed shift towards higher

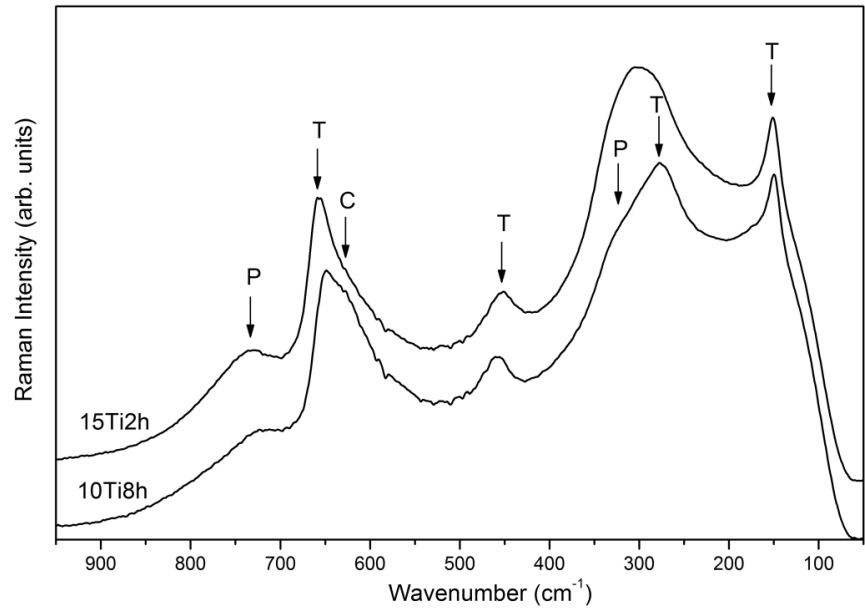

FIG. 2. FT-Raman spectra of $10 \mathrm{Ti} 8 \mathrm{~h}$ and $15 \mathrm{Ti} 2 \mathrm{~h}$. The peak characteristics for cubic zirconia, tetragonal zirconia, and disordered pyrochlore phases are indicated by $\mathrm{C}, \mathrm{T}$, and $\mathrm{P}$, respectively.

wavenumbers, when compared to pure $\mathrm{ZrO}_{2}$, can be attributed to the presence of $\mathrm{Y}^{3+}$ and $\mathrm{Ti}^{4+}$ ions in this phase.

Raman spectrum of $15 \mathrm{Ti} 2 \mathrm{~h}$ shows bands at 734, 655, 623, $452,326,272$, and $150 \mathrm{~cm}^{-1}$. As can be noticed, the Raman spectrum of this sample is similar to the Raman spectrum of 10Ti8h, indicating that also this sample is composed of the two main cubic and tetragonal zirconia phases and the disordered pyrochlore minor one. However, the bands are shifted by a few reciprocal centimeters when compared to 10Ti2h due to the slightly different chemical composition. Closer inspection of the spectra also shows that the $734 \mathrm{~cm}^{-1}$ band of 15 Ti2h is significantly more intense than the $722 \mathrm{~cm}^{-1}$ band of 10Ti8h. Stronger intensity can also be noticed for the $326 \mathrm{~cm}^{-1}$ band (due to this change the 326 and $272 \mathrm{~cm}^{-1}$ bands form one broad contour). The increase in intensity of these bands seems to suggest that the proportion of the pyrochlore phase increases with increasing concentration of $\mathrm{TiO}_{2}$ in the sample. Former studies of $\mathrm{Y}_{2} \mathrm{Ti}_{2-y} \mathrm{Zr}_{y} \mathrm{O}_{7}$ pyrochlore showed that the band above $700 \mathrm{~cm}^{-1}$ exhibits a shift towards higher wavenumbers with increasing concentration of $\mathrm{Zr}^{4+}$ ions [28]. Our spectra show that the band characteristic for the pyrochlore phase shifts from $722 \mathrm{~cm}^{-1}$ for 10 Ti8h to $734 \mathrm{~cm}^{-1}$ for 15 Ti2h. This result suggests higher concentration of $\mathrm{Zr}^{4+}$ ions in the pyrochlore phase present in our 15Ti2h sample. However, our results do not allow us to make any definite conclusions on the chemical composition of the $\mathrm{Y}_{2} \mathrm{Ti}_{2-y} \mathrm{Zr}_{y} \mathrm{O}_{7}$ pyrochlore. We may only conclude that the position and shape of the $734 \mathrm{~cm}^{-1}$ band observed for $15 \mathrm{Ti} 2 \mathrm{~h}$ are similar to those reported in the literature for $\mathrm{Y}_{2} \mathrm{Ti}_{1.1} \mathrm{Zr}_{0.9} \mathrm{O}_{7}$ [28]. This result suggests that the $15 \mathrm{Ti} 2 \mathrm{~h}$ and $10 \mathrm{Ti} 8 \mathrm{~h}$ samples contain the $\mathrm{Y}_{2} \mathrm{Ti}_{2-y} \mathrm{Zr}_{y} \mathrm{O}_{7}$ pyrochlore phase with $y$ close to 1 and slightly smaller than 1 , respectively.

TABLE III. Unit cell parameters and tetragonality of the studied samples.

\begin{tabular}{lcccc}
\hline \hline Label & Lattice parameter cubic phase $(\AA)$ & Lattice parameters tetragonal phase $(\AA)$ & Tetragonality $c_{t} / a_{t}$ \\
\hline 10Ti8h & $a_{c}=5.1210 \pm 0.0002$ & $a_{t}=3.5838 \pm 0.0006, \quad c_{t}=5.1832 \pm 0.0001$ & $1.4463 \pm 0.0003$ \\
15Ti2h & $a_{c}=5.1099 \pm 0.0006$ & $a_{t}=3.5720 \pm 0.0006, \quad c_{t}=5.1903 \pm 0.0002$ & $1.4531 \pm 0.0003$ \\
\hline \hline
\end{tabular}


The formation of the pyrochlore phase can be explained due to the extremely low Gibbs free energy formation: $-4593 \mathrm{~kJ} / \mathrm{mol}$ at $1000{ }^{\circ} \mathrm{C}$ and $-4918 \mathrm{~kJ} / \mathrm{mol}$ at $1500^{\circ} \mathrm{C}$, using the function given by Schaedler et al. [18].

\section{Field-emission scanning electron microscopy-energy dispersive x-ray (FE-SEM-EDX) studies}

A typical microstructure of the 10Ti8h duplex material sintered in air at $1500{ }^{\circ} \mathrm{C}$ for $8 \mathrm{~h}$, after polishing and thermal etching, is shown in Fig. 3(a). A typical microstructure of the 15Ti2h duplex material sintered in air at $1500{ }^{\circ} \mathrm{C}$ for $2 \mathrm{~h}$, after polishing and thermal etching, is shown in Fig. 3(b). Fully densified bodies were obtained after sintering and a bimodal grain size distribution is observed for both duplex materials. In addition, an increase in grain size is noted when titania content increases, since titania acts as a sintering aid [14,16].

Semiquantitative analysis obtained by EDX of 10Ti8h gave $\approx 78.0-82.0$ wt. $\% \mathrm{ZrO}_{2}, 11.0-15.0$ wt. $\% \quad \mathrm{Y}_{2} \mathrm{O}_{3}$, and 6.0-7.0 wt. $\% \mathrm{TiO}_{2}$ values for the large grains that can be identified as titania-doped YSZ solid solution. Meanwhile, the analysis gave $\approx 83.0-85.0$ wt. $\% \mathrm{ZrO}_{2}, 6.0-9.0$ wt. $\% \mathrm{Y}_{2} \mathrm{O}_{3}$,

(a)

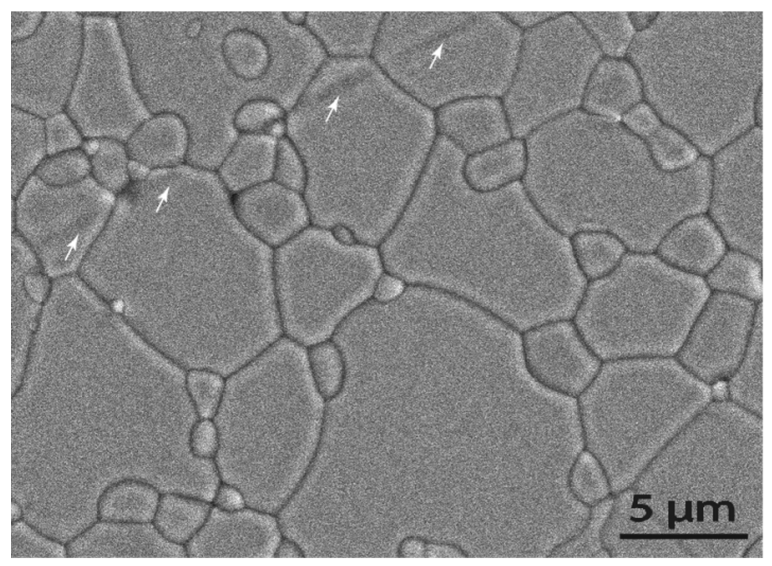

(b)

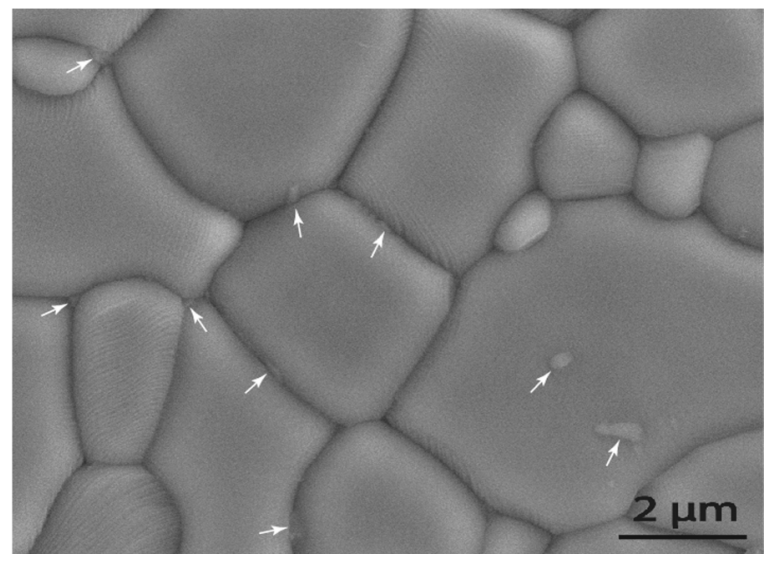

FIG. 3. FE-SEM micrographs of a polished and thermal etched surface, together with characteristic EDX analyses for (a) 10Ti8h and (b) 15Ti2h (see Table IV). The pyrochlore segregation can be observed on the surface of very few cubic grains for 10Ti8h (a). Meanwhile, for $15 \mathrm{Ti} 2 \mathrm{~h}$, the pyrochlore is clearly observed on the surface of some cubic grains and also along some grain boundaries (b).
TABLE IV. Average nominal composition obtained by EDX analysis for the two solid solutions (cubic and tetragonal grains) of each sample.

\begin{tabular}{lccc}
\hline \hline & $\mathrm{ZrO}_{2}$ (wt.\%) & $\mathrm{Y}_{2} \mathrm{O}_{3}$ (wt.\%) & $\mathrm{TiO}_{2}$ (wt.\%) \\
\hline 10Ti8h & & & \\
$\quad$ Cubic grains & 80.0 & 13.0 & 6.5 \\
$\quad$ Tetragonal grains & 84.0 & 7.5 & 7.0 \\
15Ti2h & & & \\
Cubic grains & 73.5 & 15.5 & 10.0 \\
$\quad$ Tetragonal grains & 80.5 & 6.0 & 11.5 \\
\hline \hline
\end{tabular}

and 6.0-8.0 wt.\% $\mathrm{TiO}_{2}$, values for the fine grains that could correspond to titania-doped YTZP (see Table IV). In addition, traces of crystalline segregations onto the surface of very few cubic grains are observed in Fig. 3(a), which according to the Raman studies discussed above could be attributed to the pyrochlore phase. An increase of $\mathrm{Y}_{2} \mathrm{O}_{3}$ and $\mathrm{TiO}_{2}$ and a decrease of $\mathrm{ZrO}_{2}$ is observed when the analysis is performed on those areas: 68.0-71.0 wt.\% $\mathrm{ZrO}_{2}, 19.0-22.0$ wt.\% $\mathrm{Y}_{2} \mathrm{O}_{3}$, and $10.0-11.0 \mathrm{wt} . \% \mathrm{TiO}_{2}$.

Semiquantitative analyses of $15 \mathrm{Ti} 2 \mathrm{~h}$ gave $\approx 71.0-76.0$ wt. $\% \mathrm{ZrO}_{2}, 12.0-19.0$ wt. $\% \mathrm{Y}_{2} \mathrm{O}_{3}$, and 9.0-11.0 wt.\% $\mathrm{TiO}_{2}$ values for the large grains that can be identified with titaniadoped YSZ solid solution. Meanwhile, the analysis gave $\approx 80.0-81.0$ wt. $\% \mathrm{ZrO}_{2}, 5.0-7.0$ wt. $\% \mathrm{Y}_{2} \mathrm{O}_{3}$, and 11.0-12.0 wt. $\% \mathrm{TiO}_{2}$ values for the fine grains that should correspond to titania-doped YTZP (see Table IV). Small crystalline segregations on the surface of some cubic grains and along some grain boundaries are also observed in Fig. 3(b) which, according to the Raman studies discussed above, could be attributed to the pyrochlore phase, as in the previous samples (69.0-70.0 wt.\% $\mathrm{ZrO}_{2}, 20.0-21.0$ wt. $\% \mathrm{Y}_{2} \mathrm{O}_{3}$, and 10.0 wt.\% $\mathrm{TiO}_{2}$ ). In this material, the pyrochlore phase content is more clearly observed, as was expected due to the higher amount of titanium oxide. Although, it is also a very small quantity as it can be observed in the picture. Tietz et al. [32] also detected a pyrochlore segregation for samples with the same titania content but with higher yttria content than the ones shown in this study. However, they observed the pyrochlore phase for samples sintered at lower temperatures (from 1200 to $1400^{\circ} \mathrm{C}$ ). In this paper, the amount of the pyrochlore phase is very low since it is only detected by FT-Raman and FE-SEM-EDX.

If we compare the EDX analysis of each cubic and each tetragonal phase of the two duplex materials, we conclude that the compositions of each solid solution are different from each other as was expected since the nominal composition for the materials is different for each case (see Tables II and IV).

\section{X-ray absorption spectroscopy characterization}

$\mathrm{X}$-ray absorption spectroscopy studies have been performed at the $\mathrm{Zr}$, Y, and Ti K-edges. Both XANES and EXAFS spectra have been recorded on the 2Y12T2h and 2Y12T120h tetragonal samples and on the 10Ti8h and $15 \mathrm{Ti} 2 \mathrm{~h}$ duplex samples. While 2Y12T2h is purely tetragonal, we cannot disregard a partial tetragonal-monoclinic transformation in the case of $2 \mathrm{Y} 12 \mathrm{~T} 120 \mathrm{~h}$ as it was subjected to a thermal treatment prior to the SEM studies. Thus, we have taken 
sample 2Y12T2h as our tetragonal reference. Previously recorded spectra [33] on commercial powders of $10 \% \mathrm{~mol}$ YSZ (Tosoh-Europe) and $\mathrm{ZrO}_{2}$ (Alfa Aesar, Europe), hereafter labeled c-10 and $\mathrm{C}-\mathrm{Zr}$, were also used as references for the cubic and the monoclinic phases, respectively.

The main goal of the XAS studies is to determine the local structure around the $\mathrm{Ti}$ in the cubic phase. However, this phase is only present in conjunction with the tetragonal phase in the duplex material. As x-ray absorption spectroscopy is an average technique, the coordination environment of the absorbing atom, $\mathrm{Ti}, \mathrm{Zr}$, or $\mathrm{Y}$, present in both phases will be probed simultaneously. In order to isolate the contributions coming only from those atoms in the cubic phase, we have proceeded as follows: (i) according to the characterization above, we know that the duplex materials contain a similar content of cubic and tetragonal phases, $\sim 50 \%$ each. Thus, the XAS spectra (both XANES and EXAFS) can be described as $\mathrm{XAS}_{\text {Duplex }}=0.5 \times \mathrm{XAS}_{\text {Tetra }}+0.5 \times \mathrm{XAS}_{\text {Cubic; }}$ (ii) we can use the measured spectrum of the $2 \mathrm{Y} 12 \mathrm{~T} 2 \mathrm{~h}$ sample as our $\mathrm{XAS}_{\text {Tetra }}$ reference, and we can subtract it from the spectra of the duplex materials with the appropriate $50 \%$ weighting. After this procedure, the XANES and EXAFS spectra of the cubic phase in the duplex materials should be obtained.

We have verified the validity of our approach by testing the method for the cases of the $\mathrm{Zr}$ and $\mathrm{Y}$ absorption edges. In those cases, a direct comparison with similar compounds where the cubic phase exists can be performed, although those compounds do not contain titanium. Once we have demonstrated that the method works, we have used it to extract the spectra originated from the cubic phase for the two duplex materials for the titanium case. We have then analyzed these spectra to get the local geometry around the titanium atom.

\section{Zr and $Y$ K-edge XANES and EXAFS characterization}

The comparison of the XANES spectra recorded at the $\mathrm{Zr} \mathrm{K}$ edge in all the studied samples is shown in Fig. 4(a). Although the spectra are similar for all the measured compounds, significant differences can be observed for the different phases. In all the cases, the XANES spectra are characterized by a main peak or white line split into two components, B and C, at $\sim 6.0$ and $12.0 \mathrm{eV}$ above the absorption edge, respectively (the zero of the energy scale is defined as the maximum of the first derivative of the 2Y12T2h XANES spectrum). However, it can be observed that the relative intensity of the two peaks is different for the two phases, as peak B becomes more intense in the cubic phase. Similarly, the energy position of the D and E structures shifts towards higher energies for the cubic phase. The latter results indicate the decrease of the first neighbors $\mathrm{Zr}-\mathrm{O}$ interatomic distance upon a tetragonalto-cubic transformation, in agreement with previous results found for YSZ compounds [33-38]. The variation of the B/C intensity ratio is also related to the different crystal structure. The Zr K-edge XANES spectra of three zirconia polymorphs [34] are shown in the inset of Fig. 4(a). It can be seen that the shape and the relative intensity of the two-peak structure of the main absorption line are clearly different for both tetragonal and cubic phases. The comparison of our spectra with those shown in the inset supports that the signal extracted from the
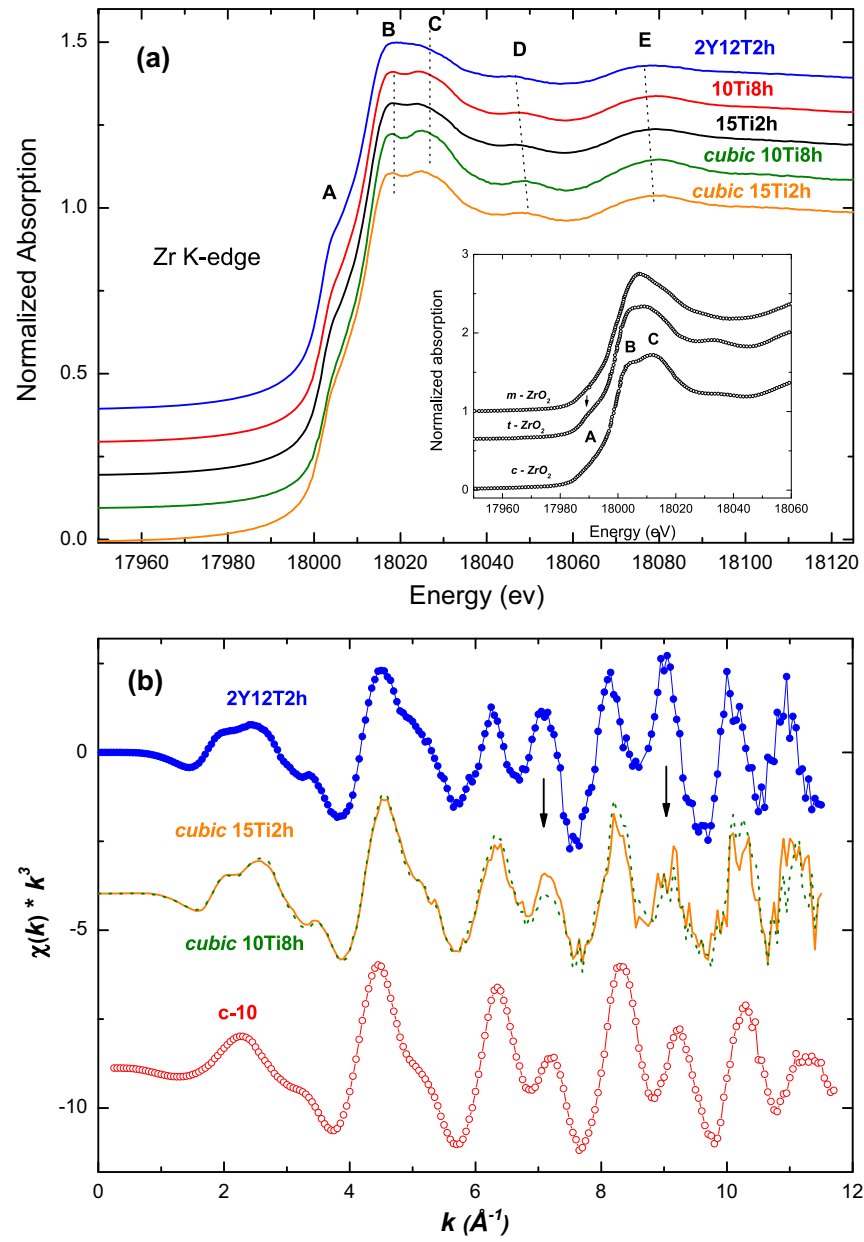

FIG. 4. (Color online) (a) Comparison between the normalized $\mathrm{Zr}$ K-edge XANES spectra of the tetragonal 2Y12T2h sample and that of the duplex materials: 10Ti8h and 15Ti2h. The comparison also includes the XANES spectra corresponding to the cubic phase of the duplex materials (see text for details). The Zr K-edge XANES spectra of zirconia polymorphs is shown in the inset for comparison (from Ref. [34]). (b) Comparison between the $\mathrm{Zr} \mathrm{K}$-edge $\mathrm{k}^{3}$-weighted EXAFS signal of the tetragonal $2 \mathrm{Y} 12 \mathrm{~T} 2 \mathrm{~h}$ sample, the cubic c-10 reference, and that of the cubic phase in the 10Ti8h and $15 \mathrm{Ti} 2 \mathrm{~h}$ duplex materials.

duplex material following the procedure described above really corresponds to a cubic phase.

The validity of the aforesaid procedure to isolate the XAS spectra of the cubic phase in the duplex materials is also confirmed by the comparison of the EXAFS spectra. As shown in Fig. 4(b), the $\mathrm{Zr} \mathrm{K}$-edge $\mathrm{k}^{3}$-weighted EXAFS signals of both tetragonal 2Y12T2h and cubic YZS c-10 samples show differences in the relative intensity of several spectral features, marked with arrows in Fig. 4(b) [33-37]. This comparison clearly shows the coincidence of the EXAFS spectra of both the cubic phase in the 10Ti8h and 15Ti2h duplex samples and of the cubic c-10 sample, which increases the level of confidence in the procedure we have followed.

A final confirmation of the reliability of the method used has been obtained by the fitting of the EXAFS signals (see Supplemental Material for details of the EXAFS analysis [39]). 

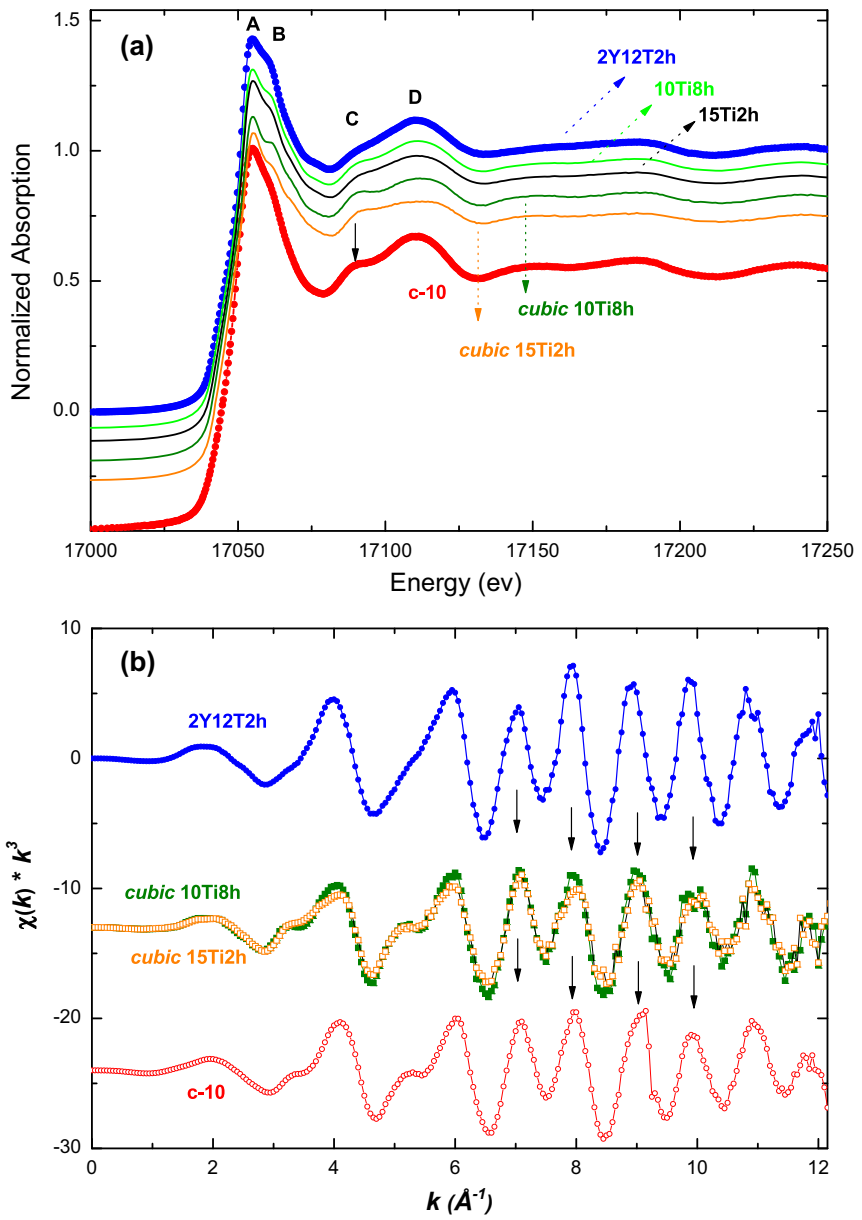

FIG. 5. (Color online) (a) Comparison between the normalized Y K-edge XANES spectra of the tetragonal 2Y12T2h sample, duplex 10Ti8h and 15Ti2h samples, cubic YSZ reference c-10, and that of the cubic phases extracted from the duplex materials. (b) Y K-edge $\mathrm{k}^{3}$-weighted EXAFS signals of the tetragonal 2Y12T2h sample, cubic c-10 reference, and that of the cubic phases extracted from the duplex materials.

Similar results probing the cubic versus tetragonal character of the samples have been found at the Y K-edge (see Fig. 5). As in the case of the $\mathrm{Zr} \mathrm{K}$-edge, the Y K-edge XANES spectra in Fig. 5(a) show differences for the tetragonal and the cubic phases, such as the intensity ratio of the two peaks of the main absorption line $(\mathrm{A}, \mathrm{B})$ and those of the broad spectral feature appearing at $\sim 40 \mathrm{eV}$ (C) and $\sim 60 \mathrm{eV}$ (D) above the absorption edge. A comparison of the XANES spectra clearly indicates that the signals extracted from the duplex materials correspond to a cubic phase. The same results are found in the inspection of the extracted EXAFS signals shown in Fig. 5(b). As in the case of the $\mathrm{Zr} \mathrm{K}$-edge, the EXAFS analysis of the first coordination shell has been performed [39]. In both Zr and Y K-edge, the results are in agreement with previous reports showing the differences between the cubic and tetragonal phases.

These results show that the signals extracted from the XAS spectra of the duplex materials by subtracting the correct amount corresponding to the tetragonal phase are those of a cubic phase. The validity of our procedure allows us to perform the same analysis at the Ti K-edge, aimed to determine the differences in the local structure of $\mathrm{Ti}$ in both cubic and tetragonal phases.

\section{Ti K-edge XANES and EXAFS characterization}

The XANES spectra recorded at the Ti K-edge on the studied samples are shown in Fig. 6. The signals of the cubic phase, extracted from the spectra of the duplex materials following the procedure explained above, have also been included for comparison.

The visual inspection of the XANES spectra indicates that the local environment of the titanium atoms is different for the cubic and for the tetragonal phases. In addition, interesting differences are found in the intensity of the pre-edge peak observed in the XANES spectra at energies around $4970 \mathrm{eV}$. According to the literature, this peak should be very weak or absent in the case of a regular sixfold Ti-O arrangement, as occurring in the $\mathrm{Y}_{2} \mathrm{Ti}_{2} \mathrm{O}_{7}$ pyrochlore reference compound (see inset in Fig. 6) [23], while a very sharp feature should be present in the case of fivefold or tetrahedral structures [23,40,41], with an expected intensity much higher than the observed ones in the systems under study. Indeed, the observed increase of the prepeak intensity in the duplex samples when comparing with the symmetric pyrochlore case is in agreement with the occurrence of a distorted Ti-O arrangement or with an offcenter displacement of the $\mathrm{Ti}$ atom within the octahedral $\mathrm{TiO}_{6}$ local bonding unit $[42,43]$. According to the XANES results reported in Fig. 6, the maximum distortion should correspond to the tetragonal phase, and this distortion decreases in the cubic phase as indicated by the decrease of the prepeak intensity.

These results have been confirmed by the analysis of the EXAFS spectra. As shown in Fig. 7, the EXAFS spectra also indicate that the local Ti-O environment is different for the cubic and for the tetragonal phases. This is further illustrated in Fig. 8 where the Fourier-filtered EXAFS signals corresponding to the next-neighboring Ti-O arrangement in all the studied

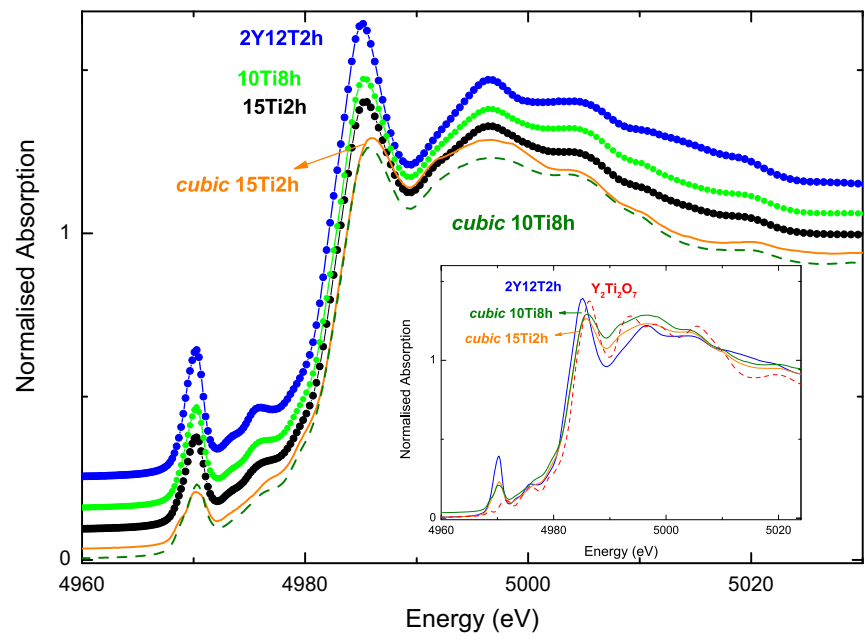

FIG. 6. (Color online) Normalized XANES spectra at the Ti Kedge of the tetragonal $2 \mathrm{Y} 12 \mathrm{~T} 2 \mathrm{~h}$ sample and of the duplex materials. The cubic phases extracted from the duplex samples have been added for comparison. For the sake of completion, the spectrum of the $\mathrm{Y}_{2} \mathrm{Ti}_{2} \mathrm{O}_{7}$ pyrochlore obtained by solid state methods (from Ref. [23]) has been included in the comparison shown in the inset. 


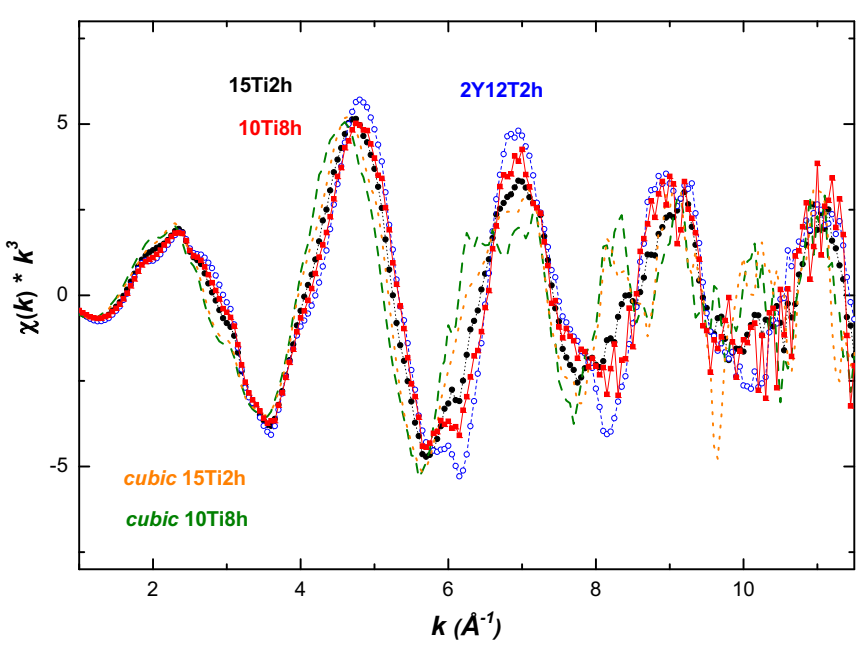

FIG. 7. (Color online) Comparison between the experimental Ti K-edge $\chi(\mathrm{k}) * \mathrm{k}^{3}$ EXAFS signals of the tetragonal 2Y12T2h (o) and

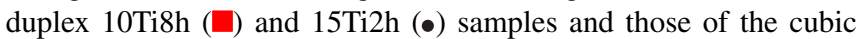
phase extracted from the duplex materials (see text for details).
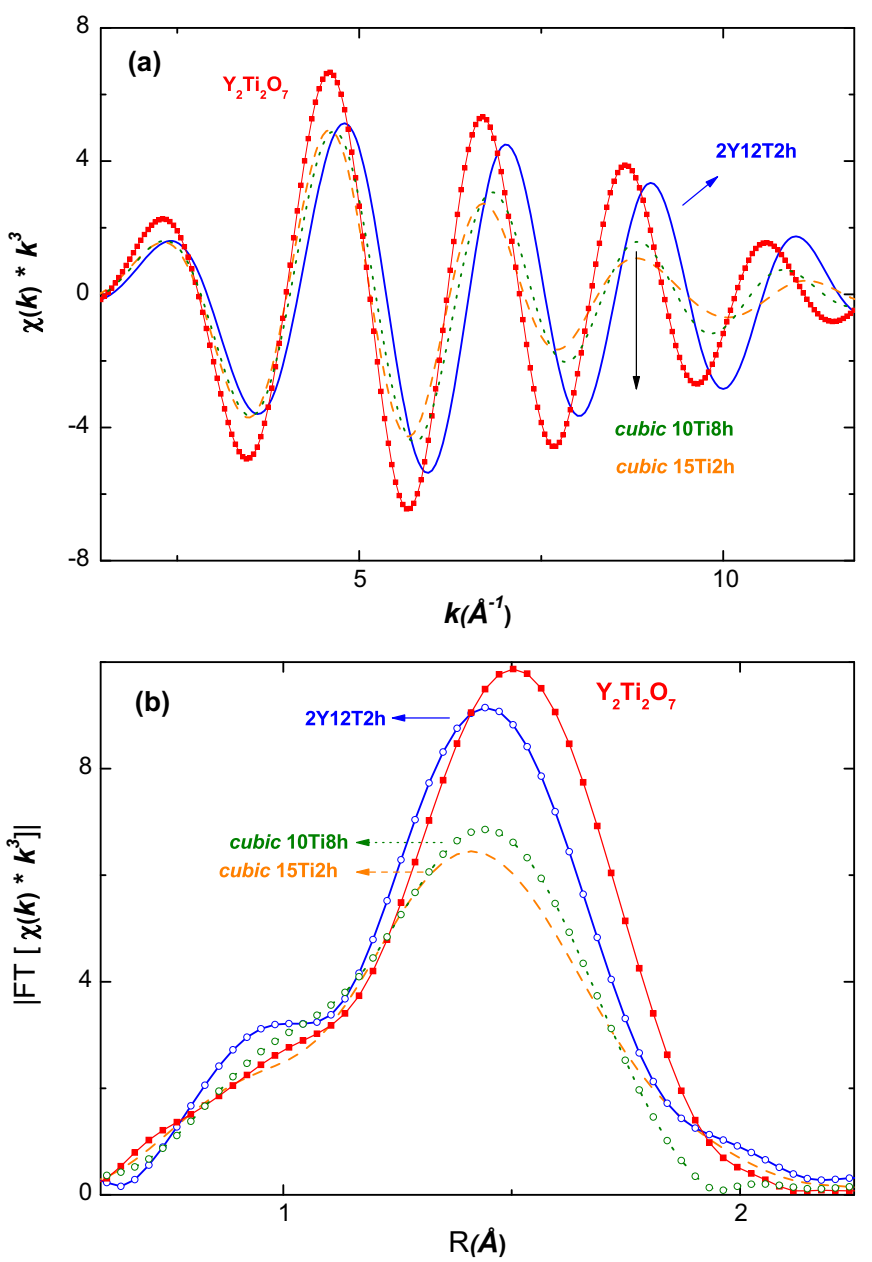

FIG. 8. (Color online) (a) Fourier-filtered Ti K-edge $\mathrm{k}^{3}$-weighted EXAFS signals of the tetragonal $2 \mathrm{Y} 12 \mathrm{~T} 2 \mathrm{~h}$, the cubic phase extracted from the duplex materials, and the $\mathrm{Y}_{2} \mathrm{Ti}_{2} \mathrm{O}_{7}$ pyrochlore (from Ref. [23]). (b) Modulus of their corresponding Fourier transforms.
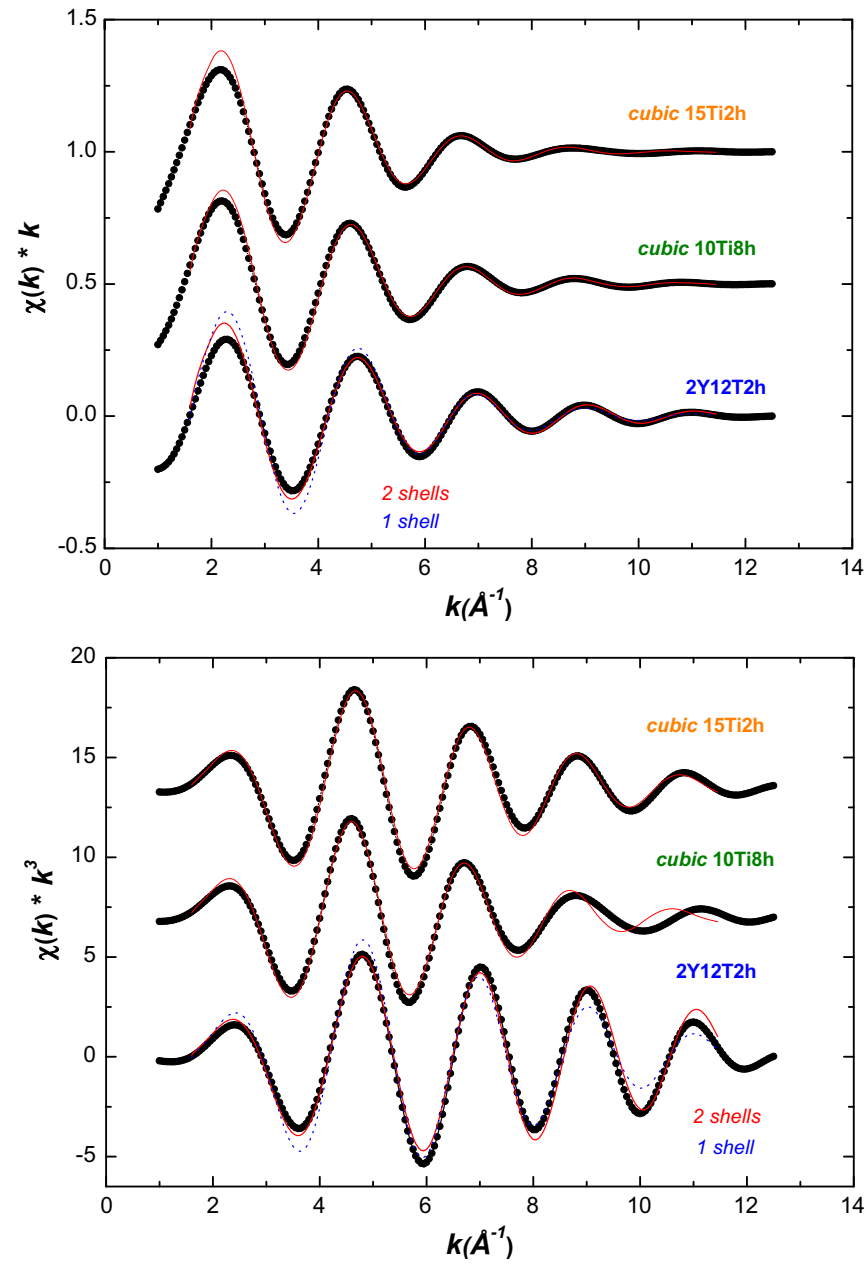

FIG. 9. (Color online) k-weighted (top) and $\mathrm{k}^{3}$-weighted (bottom) filtered EXAFS data (circles) and best fit obtained with parameters included in Table V (solid line).

compounds are compared to that of the reference $\mathrm{Y}_{2} \mathrm{Ti}_{2} \mathrm{O}_{7}$ pyrochlore. As shown in Fig. 8, the EXAFS signals extracted for the cubic phase in the duplex materials are similar to that of the $\mathrm{Y}_{2} \mathrm{Ti}_{2} \mathrm{O}_{7}$ reference, showing a regular Ti-O arrangement, although the damping of these signals indicate the existence of an increased disorder in the cubic phases with respect to the pyrochlore.

These effects have been quantified by the fitting of the EXAFS signals that was performed in k-space only for the contribution of the first coordination shell. Thus, the EXAFS contribution of this shell was isolated by Fourier filtering in the range from $0.6 \leq R \leq 2.06 \AA$. The difference on the local environments of the titanium atoms in the studied samples was assessed by analyzing the filtered EXAFS signals. The results of the fits are shown in Fig. 9, and the best-fit parameters are summarized in Table V. For the EXAFS analysis, only two parameters were allowed to vary during the fitting procedure: the Ti-O interatomic distance, $r_{\mathrm{Ti}-\mathrm{O}}$, and the Debye-Waller factor, $\sigma^{2}$, relative to that of the reference sample. In the first instance, the interatomic distances were fixed equal to those of the reference sample, but they were then allowed to vary. An integer coordination number value was imposed during the fitting procedure for all the samples, except in the 
TABLE V. Best fit parameters obtained from the analysis of the first shell contribution to the Ti K-edge EXAFS spectra: $N_{\text {coord }}$ : coordination number; $r_{\mathrm{Ti}-\mathrm{O}}$ : distance Ti-O; $\Delta \sigma_{\mathrm{Ti}-\mathrm{O}}^{2}$ : Debye-Waller factor relative to that of the corresponding reference sample; $R$ : reliability factor [44].

\begin{tabular}{lcccc}
\hline \hline Sample & $N_{\text {coord }}($ fixed $)$ & $r_{\text {Ti-O }}(\AA)$ & $\Delta \sigma^{2}{ }_{\text {Ti-O }}\left(\AA^{2}\right)$ & $R$ \\
\hline $\mathrm{Y}_{2} \mathrm{Ti}_{2} \mathrm{O}_{7}$ & 6.0 & 1.96 & & \\
10Ti8h & 5.6 & $1.95 \pm 0.01$ & $0.006 \pm 0.001$ & 0.008 \\
10Ti8h & 6.0 & $1.95 \pm 0.01$ & $0.006 \pm 0.001$ & 0.009 \\
10Ti8h & 5.0 & $1.95 \pm 0.01$ & $0.005 \pm 0.001$ & 0.009 \\
15Ti2h & 5.0 & $1.93 \pm 0.01$ & $0.004 \pm 0.001$ & 0.010 \\
15Ti2h & 6.0 & $1.93 \pm 0.01$ & $0.008 \pm 0.001$ & 0.014 \\
Tetra & 6.0 & $1.89 \pm 0.02$ & $0.003 \pm 0.002$ & 0.050 \\
Tetra & 4.0 & $1.88 \pm 0.015$ & $0.003 \pm 0.001$ & 0.014 \\
& 2.0 & $2.21 \pm 0.015$ & $0.006 \pm 0.002$ & \\
Tetra & 5.0 & $1.90 \pm 0.015$ & $0.004 \pm 0.001$ & 0.011 \\
& 1.0 & $2.24 \pm 0.015$ & $0.004 \pm 0.002$ & \\
\hline \hline
\end{tabular}

Filtering range: $1.6 \leq k \leq 11.4 \AA^{-1} ; 0.6 \leq R \leq 2.06 \AA$. Fitting range: $1.6 \leq k \leq 11.4 \AA^{-1}$.

case of $10 \mathrm{Ti} 8 \mathrm{~h}$, where a coordination number equal to 5.6 was used in one of the analysis trials (see Table V). For the sake of completeness, the fits were performed on both k- and $\mathrm{k}^{3}$-weighted EXAFS signals.

The EXAFS analysis shows that, in the case of the 10Ti8h sample, there are no appreciable differences in the quality of the fits obtained by fixing the coordination number either to 6 or 5 and varying the Debye-Waller factors. Indeed, the best fit is obtained for an intermediate 5.6 coordination number. In contrast, in the case of the $15 \mathrm{Ti} 2 \mathrm{~h}$ sample, i.e. increasing the Ti content, the best fit is obtained for a $N=5$ coordination number. However, this difference needs to be considered with caution as there is a strong correlation between the EXAFS coordination numbers and the Debye-Waller factors used to account for the disorder. Thus, the fact that the EXAFS amplitude of the cubic phase in the 10Ti8h sample is smaller than that of the cubic phase for the 15Ti2h sample can be explained as an increasing disorder of the Ti-O octahedral when increasing the titanium content. The same can be applied when comparing the amplitude of the EXAFS signals of the cubic phases of the duplex samples with the signals extracted from both the tetragonal phase and the $\mathrm{Y}_{2} \mathrm{Ti}_{2} \mathrm{O}_{7}$ pyrochlore. As shown in Table V, the evolution of the Debye-Waller factors found in the fitting process agree with this view, being higher for the cubic phases than for the tetragonal one, although the latter is more distorted.

The combined XANES and EXAFS results indicate that starting from the strongly distorted sixfold coordination of $\mathrm{Ti}$ in the tetragonal phase (4 oxygen atoms at $1.88 \AA$ plus 2 oxygen atoms at $2.21 \AA$ ), the Ti environment in the cubic phase evolves through a more regular structure with a single Ti-O interatomic distance (1.93 $\AA$ for $15 \mathrm{Ti} 2 \mathrm{~h}$ and $1.95 \AA$ for $10 \mathrm{Ti} 8 \mathrm{~h})$ close to this found in the case of pyrochlores or in both rutile and anatase structures (1.95-1.96 $\AA$ ). As the distortion decreases in the cubic phase with respect to the tetragonal one, the prepeak intensity decreases, and the first main-edge peak shifts to higher energies, in agreement with the EXAFS behavior.

\section{E. ac electrical measurements: impedance spectroscopy measurements in air}

Due to the duplex nature of the samples, there is an obvious difficulty in analyzing impedance data in terms of grain and grain boundary contributions. Consequently, preferential attention is given to the total conductivity of the different materials. The Arrhenius plot in Fig. 10 shows an increase of the total resistance of the materials for increasing titania content (15Ti2h versus 10Ti8h). For the sake of comparison, the total ionic conductivities of YSZ and YTZP are also shown. A conductivity drop of 5 times and 13.5 times at $1000^{\circ} \mathrm{C}$ $(x=0.79)$ is observed between YSZ and 10Ti8h and YSZ and $15 \mathrm{Ti} 2 \mathrm{~h}$, respectively. This behavior cannot be accounted for in terms of a dilution effect. The substitution of $\mathrm{Zr}^{4+}$ by $\mathrm{Ti}^{4+}$ does not account for an increase of the ionic defects, as titanium is a tetravalent dopant. The concentration of oxygen vacancies is thus determined by the concentration of yttrium, that is $4 \mathrm{~mol} \%$ of oxygen vacancies for YSZ, $3.6 \mathrm{~mol} \%$ for 10Ti8h, and $3.4 \mathrm{~mol} \%$ for $15 \mathrm{Ti} 2 \mathrm{~h}$. This means that only a slight overall decrease in concentration of ionic defects should be noticed between undoped (YSZ) and duplex materials, as a consequence of a simple dilution effect. This alone cannot account for the values of conductivity drops reported in Fig. 10 for the duplex materials. In addition, YTZP material has an oxygen vacancy concentration of $1.5 \mathrm{~mol} \%$, and its total conductivity only drops 1 time with respect to $\mathrm{YSZ}$ at $1000^{\circ} \mathrm{C}$.

The values of the total activation energy for YSZ and YTZP are $1.02 \pm 0.01 \mathrm{eV}$ and $0.87 \pm 0.01 \mathrm{eV}$, respectively, while for the duplex samples those values are $0.89 \pm 0.02 \mathrm{eV}$ for $10 \mathrm{Ti} 8 \mathrm{~h}$ and $0.93 \pm 0.03 \mathrm{eV}$ for $15 \mathrm{Ti} 2 \mathrm{~h}$. Thus, the activation energy for ionic migration in 10Ti8h and $15 \mathrm{Ti} 2 \mathrm{~h}$ is lower than that for YSZ but higher than that for YTZP. This is reasonable since both materials are constituted by $0.5 \mathrm{~mol}$ fraction of YSZ and 0.5 mol fraction of YTZP. An average activation energy value would be $0.95 \pm 0.02 \mathrm{eV}$, close to the values obtained for the duplex materials.

These results, combined with the structural XAS characterization, provide a better understanding of the role of titania on the ionic transport properties of these zirconia-based solid

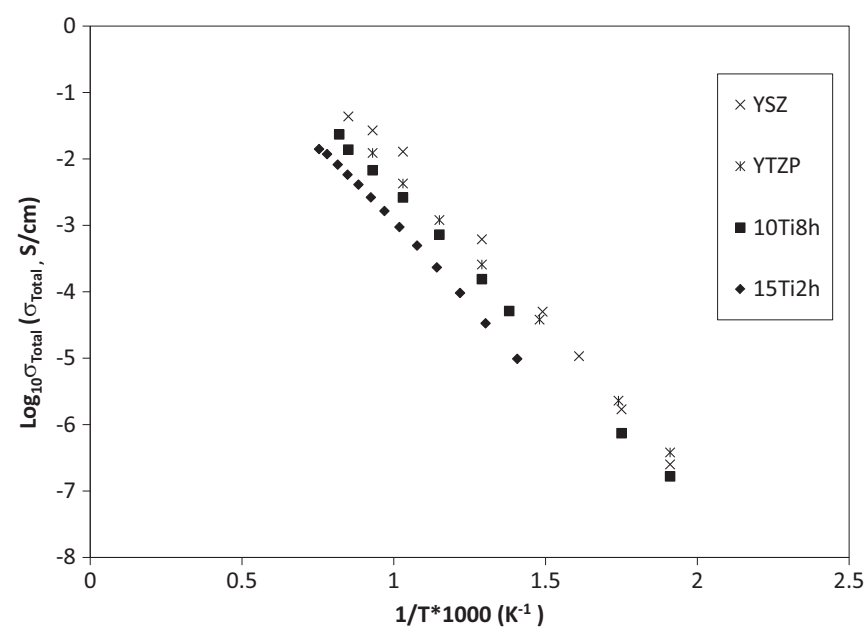

FIG. 10. Logarithm of the total conductivities of YSZ, YTZP, 10Ti2h, and $15 \mathrm{Ti} 8 \mathrm{~h}$ in air as a function of the reciprocal of the temperature. 
solutions. X-ray absorption spectroscopy results, both XANES and EXAFS, confirm that Ti shows a sixfold coordination, i.e. clearly departing from the eightfold one expected for a simple substitution at the $\mathrm{Zr}$ sites. As a consequence, Ti can trap some oxygen vacancies [45], which results in an overall decrease in the concentration of mobile oxygen vacancies, in agreement with the observed electrical conductivity decrease. Moreover, our results also indicate a higher disorder of the Ti-O arrangement in the cubic phase than for the tetragonal one, which is in agreement with the further reduction of the electrical conductivity observed in the duplex materials with respect to the undoped YSZ and undoped YTZP materials.

\section{CONCLUSIONS}

The use of different processing strategies has allowed us to synthesize duplex materials in the $\mathrm{ZrO}_{2}-\mathrm{Y}_{2} \mathrm{O}_{3}-\mathrm{TiO}_{2}$ ternary system. In addition to titania-doped YSZ solid solution and titania-doped YTZP solid solution, $\mathrm{Y}_{2}\left(\mathrm{Ti}_{1-y} \mathrm{Zr}_{y}\right)_{2} \mathrm{O}_{7}$ pyrochlore is present as a minor phase with $y$ close or slightly smaller than 1 , according to FT-Raman results. Fieldemission scanning electron microscopy images show this minor pyrochlore phase on the surface of very few cubic grains for 10Ti8h. Meanwhile, for $15 \mathrm{Ti} 2 \mathrm{~h}$, the pyrochlore is on the surface of some cubic grains and also along some grain boundaries. This phase is more clearly observed in the case of the 15Ti2h duplex material, as expected due to the higher amount of titanium oxide.

The activation energy for ionic migration in 10Ti8h and $15 \mathrm{Ti} 2 \mathrm{~h}$ is lower than that for YSZ but higher than that for YTZP. This is not surprising since both materials are constituted by $0.5 \mathrm{~mol}$ fraction of YSZ and $0.5 \mathrm{~mol}$ fraction of YTZP, from which an average activation energy value of
$0.95 \pm 0.02 \mathrm{eV}$ is expected. A total ionic conductivity drop of 5 and 13.5 times is observed between YSZ and the duplex materials $10 \mathrm{Ti} 8 \mathrm{~h}$ and $15 \mathrm{Ti} 2 \mathrm{~h}$, respectively. This behavior cannot be accounted for in terms of a dilution effect, which points out to the role played by the local structure of Ti.

X-ray absorption spectroscopy results, both XANES and EXAFS, indicate that the local structural environment of $\mathrm{Ti}$ in both the cubic and tetragonal phases of the duplex materials corresponds to a sixfold Ti-O arrangement, departing from the eightfold coordination expected if a simple substitution at the $\mathrm{Zr}$ sites would take place. Starting from the strongly distorted sixfold coordination of $\mathrm{Ti}$ in the tetragonal phase, the $\mathrm{Ti}$ environment in the cubic phase evolves through a more regular structure with a single Ti-O interatomic distance, resembling that of pyrochlores or both rutile and anatase structures. Moreover, in the case of the cubic phase, these results also indicate that the Ti-O coordination polyhedron becomes more disordered as the Ti content increases. All in all, these results indicate that $\mathrm{Ti}$ ions would trap oxygen vacancies resulting in the overall decrease of the electrical conductivity in the titania-doped materials with respect to the undoped materials, in agreement with the electrical conductivity behavior.

\section{ACKNOWLEDGMENTS}

This work has been supported by MINECO (Spain) through the projects MAT2012-31090 and MAT2011-27573-C04-04, and by the Aragón DGA NETOSHIMA grant. The authors thank Diamond Light Source Ltd for access to the Versatile X-ray Absorption Spectroscopy Beamline, I20. We also wish to thank C. Díaz-Dorado for the micrographs composition of this work. RB acknowledges support from the Ministerio de Economía y Competitividad of Spain.
[1] E. J. L. Schouler, Solid State Ionics 9-10, 945 (1983).

[2] N. Bonanos, R. K. Slotwinski, B. C. H. Steele, and P. Butler, J. Mater. Sci. Lett. 3, 245 (1984).

[3] R. P. Ingel, D. Lewis, B. A. Bender, and R. W. Rice, J. Am. Ceram. Soc. 65, C150 (1982).

[4] A. S. Nowick, Diffusion in Crystalline Solids, edited by G. E. Murch and A. S. Nowick (Academic Press, Orlando, FL, 1984), Chap. 3.

[5] S. S. Liou and W. L. Worrell, Appl. Phys. A 49, 25 (1989).

[6] R. M. C. Marques, J. R. Frade, and F. M. B. Marques, in Proceedings of the Euroceramics II, edited by G. Ziegler and H. Hausner (Deutsche Keramische Gesellschaft e. V., Augsburg, 1991), Vol. 3, p. 2179.

[7] R. M. C. Marques, J. R. Frade, and F. M. B. Marques, in Proceedings of the Third International Symposium on Solid Oxide Fuel Cells, edited by S. C. Singhal and H. Iwahara (The Electrochem. Soc. Inc., Pennington, NJ, 1993), Vol. 93-94, p. 513.

[8] M. T. Colomer, R. M. C. Marques, J. R. Jurado, and F. M. B. Marques, Mat. Res. Bull. 30, 515 (1995).

[9] M. T. Colomer and J. R. Jurado, J. Solid State Chem. 165, 79 (2002).

[10] X. Mantzouris, N. Zouvelou, V. A. C. Haanappel, F. Tietz, and P. Nikolopoulos, J. Mater. Sci. 42, 10152 (2007).
[11] B. J. Chen and Z. Q. Zeng, Key Engin. Mat. 336-338, 2254 (2007).

[12] H. Miyazaki, Int. J. Appl. Ceram. Tech. 5, 490 (2008).

[13] E. Zschech, P. N. Kountouros, G. Petzow, P. Behrens, A. Lessmann, and R. Frahm, J. Amer. Ceram. Soc. 76, 197 (1993).

[14] M. T. Colomer and M. Mirek, J. Solid State Chem. 184365 (2011).

[15] F. Capel, C. Moure, P. Durán, A. R. González-Elipe, and A. Caballero, Ceram. Intern. 25, 639 (1999).

[16] M. T. Colomer, P. Durán, A. Caballero, and J. R. Jurado, Mat. Sci. Eng. A 229, 114 (1997).

[17] A. J. Feighery, J. T. S. Irvine, D. P. Fagg, and A. Kaiser, J. Solid State Chem. 143, 273 (1999).

[18] T. A. Schaedler, O. Fabrichnaya, and C. G. Levi, J. Europ. Ceram. Soc. 28, 2509 (2009).

[19] R. A. Miller, J. L. Smialek, and R. G. Garlick, in Advances in Ceramics edited by A. H. Heuer and L. W. Hobbs (Amer. Ceram. Soc., Columbus, OH, 1981), Vol. 3, pp. 241-253.

[20] D. E. Sayers and B. A. Bunker, in X-Ray Absorption: Principles, Applications, Techniques of EXAFS, SEXAFS, and XANES, edited by D. C. Koningsberger and R. Prins (Wiley, New York, 1988), Chap. 6.

[21] B. Ravel and M. Newville, J. Synchrotron Rad. 12, 537 (2005).

[22] K. V. Klementiev, J. Phys. D: Appl. Phys. 34, 209 (2001). 
[23] M. L. Sanjuán, C. Guglieri, S. Díaz-Moreno, G. Aquilanti, A. F. Fuentes, L. Olivi, and J. Chaboy, Phys. Rev. B 84, 104207 (2011).

[24] P. H. Citrin, P. Eisenberger, and B. M. Kincaid, Phys. Rev. Lett. 36, 1346 (1976).

[25] S. I. Zabinsky, J. J. Rehr, A. Ankudinov, R. C. Albers, and M. J. Eller, Phys. Rev. B 52, 2995 (1995).

[26] T. Hirata, E. Asari, and M. Kitajima, J. Solid State Chem. 110, 201 (1994).

[27] M. Glerup, O. F. Nielsen, and F. W. Poulsen, J. Solid State Chem. 160, 25 (2001).

[28] K. J. Moreno, A. F. Fuentes, M. Maczka, J. Hanuza, U. Amador, J. Santamaria, and C. Leon, Phys. Rev. B 75, 184303 (2007).

[29] N. J. Hess, B. D. Begg, S. D. Conradson, D. E. McCready, P. L. Gassman, and W. J. Weber, J. Phys. Chem. B 106, 4663 (2002).

[30] F. X. Zhang, J. W. Wang, M. Lang, J. M. Zhang, and R. C. Ewing, J. Solid State Chem. 183, 2636 (2010).

[31] F. X. Zhang and S. K. Saxena, Chem. Phys. Lett. 413, 248 (2005).

[32] F. Tietz, W. Jungen, P. Lersch, M. Figaj, K. D. Becker, and D. Skarmoutsos, Chem. Mater. 14, 2252 (2002).

[33] O. J. Dura, R. Boada, M. A. López de la Torre, G. Aquilanti, A. Rivera-Calzada, C. León, and J. Chaboy, Phys. Rev. B 87, 174109 (2013).
[34] P. Li, I.-W. Chen, and J. E. Penner-Hahn, Phys. Rev. B. 48, 10063 (1993); 48, 10082 (1993).

[35] G. E. Rush, A. V. Chadwick, I. Kosacki, and H. U. Anderson, J. Phys. Chem. B 104, 9597 (2000).

[36] W. Yuren, L. Kunquan, W. Dazhi, W. Zhonghua, and F. Zhengzhi, J. Phys.: Condens. Matter 6, 633 (1994).

[37] O. J. Dura, M. A. López de la Torre, L. Vázquez, J. Chaboy, R. Boada, A. Rivera-Calzada, J. Santamaria, and C. Leon, Phys. Rev. B 81, 184301 (2010).

[38] P. Li, I.-W. Chen, and J. E. Penner-Hahn, Phys. Rev. B. 48, 10074 (1993)

[39] See Supplemental Material at http://link.aps.org/supplemental/ 10.1103/PhysRevB.89.094101 for details of the EXAFS analysis.

[40] F. Farges, G. E. Brown, and J. J. Rehr, Phys. Rev. B 56, 1809 (1997).

[41] J. Chaboy, N. Nakajima, and Y. Tezuka, J. Phys.: Condens. Matter 19, 266206 (2007).

[42] A. I. Frenkel, M. H. Frey, and D. A. Payne, J. Synchrotron Rad. 6, 515 (1999)

[43] A. I. Frenkel, Y. Feldman, V. Lyahovitskaya, E. Wachtel, and I. Lubomirsky, Phys. Rev. B 71, 024116 (2005).

[44] The reliability factor $R$ corresponds to the fractional misfit as defined in the ARTEMIS package (Ref. [21]).

[45] L. S. M. Traqueia, T. Pagnier, and F. M. B. Marques, J. Eur Ceram. Soc. 17, 1019 (1997). 